\title{
Family Medicine and Community Health \\ Postgraduate education among family and community physicians in Brazil: the Trajetórias MFC project
}

\author{
Leonardo Ferreira Fontenelle (D) , ${ }^{1}$ Stephani Vogt Rossi (D) , 1 \\ Miguel Henrique Moraes de Oliveira (1) , ${ }^{1}$ Diego José Brandão (1) ,2 \\ Thiago Dias Sarti (D) $^{3}$
}

To cite: Fontenelle LF, Rossi SV, Oliveira MHM, et al. Postgraduate education among family and community physicians in Brazil: the Trajetórias MFC project. Fam Med Com Health 2020;8:e000321. doi:10.1136/ fmch-2020-000321
Check for updates

(c) Author(s) (or their employer(s)) 2020. Re-use permitted under CC BY-NC. No commercial re-use. See rights and permissions. Published by BMJ.

${ }^{1}$ Medical School, Universidade Vila Velha, Vila Velha, Brazil

${ }^{2}$ Commission of Medical Residency, Universidade Vila Velha, Vila Velha, Brazil

${ }^{3}$ Department of Social Medicine, Universidade Federal do Espirito Santo, Vitoria, Brazil

Correspondence to Professor Leonardo Ferreira Fontenelle;

leonardof@leonardof.med.br

\section{ABSTRACT}

Objective Our objective was to describe the postgraduate education trajectories of family and community physicians in Brazil, where neither primary healthcare nor family and community medicine is recognised as a knowledge area for the purpose of research and postgraduate education (master's and PhD degrees).

Design An observational, exploratory study, using administrative data. A nationwide list of family and community physicians as of late November 2018 was compiled from multiple sources. Data on the mode of specialisation was obtained from the same sources and were correlated with data on master's and PhD degrees, obtained from the curricula vitae on the Lattes Platform. Setting This study was set in Brazil.

Participants 6238 family and community physicians (58.3\% female), of whom 2795 had earned a specialist certificate (identified from the list of physicians certified by Sociedade Brasileira de Medicina de Família e Comunidade) and 3957 had completed medical residency (identified from SisCNRM, the national information system for medical residency).

Results A master's degree was held by 747 (12.0\%) family and community physicians, and a $\mathrm{PhD}$ by 170 $(2.7 \%)$; most degrees were in collective health $(47.0 \%$ and $42 \%$, respectively). Men were more likely than women to hold a master's degree (adjusted odds ratio (aOR) 1.24, $95 \%$ uncertainty interval (UI) 1.07-1.45) and even more likely to a hold PhD (aOR 1.86, 95\% Ul 1.35-2.59). Family and community physicians were also less likely to hold a $\mathrm{PhD}$ degree if their master's degree was professional (oriented towards jobs outside academia) instead of academic (aOR 0.15, 95\% UI 0.05-0.39) or in some area other than collective health or medicine (aOR 0.41, $95 \%$ UI 0.21-0.78, compared with a master's degree in collective health). The postgraduate degree was more likely to precede specialisation for family and community physicians specialising through certification (master's degree $39.9 \%$, PhD 33\%) than through medical residency (master's degree 9.1\%, PhD 6\%).

Conclusion Family and community physicians in Brazil increasingly earn academic and professional master's and $\mathrm{PhD}$ degrees, with an emphasis on collective health, even though women seemingly face barriers to advance their education. The consequences of different postgraduate trajectories should be critically examined.

\section{Key points}

\section{Question}

What are the trajectories in postgraduate education of Brazilian family and community physicians?

\section{Finding}

- Most master's and $\mathrm{PhD}$ degrees are in collective health, not medicine or other areas.

- Professional master's degrees (oriented towards jobs outside academia), master's degrees not in medicine and female gender are less likely to result in a $\mathrm{PhD}$ degree.

- Sometimes the master's or PhD degree is earned before specialisation in family and community medicine, more so for specialisation through certification than for through residency.

\section{Meaning}

- Barriers to postgraduate education among female family and community physicians should be identified and removed.

- Outcomes of different postgraduate trajectories should be studied, both inside and outside academia.

\section{INTRODUCTION}

In the second half of the 20th century, family medicine differentiated from general practice as a result of the increased appreciation of the importance of primary healthcare, the psychosocial aspects of health and the complexity of causation. ${ }^{1-3}$ 'General practitioners' in countries such as the UK and the Netherlands are expected to undergo vocational training (medical residency), and thus are family physicians by another name. ${ }^{4-6}$

In Brazil, emphasis on primary healthcare coincided with the fight for redemocratisation, culminating in the establishment of a national health system called Sistema Único de Saúde (SUS; Unified Health System). ${ }^{17-10}$ Meanwhile, in the 1970s, movements called community medicine (medicina comunitária) and comprehensive medicine (medicina integral) merged into a medical specialty then 
called community general medicine (medicina geral comunitária). ${ }^{17-9}$ In 2000-2001, after SUS started expanding access to primary healthcare through the Family Health Strategy (then Family Health Programme, conceived based on community general medicine and other inputs $^{71112}$ ), community general medicine resolved its differences with family medicine, resulting in a medical specialty now called family and community medicine (medicina de família e comunidade, MFC).${ }^{18}$ Preventive and social medicine (medicina preventiva e social) remains a separate specialty, despite the partially overlapping scope of practice. ${ }^{1}$

The concepts of 'field of competence' and 'core competence ${ }^{13}$ have been considered useful for understanding the interplay between the disciplines of primary healthcare and family and community medicine. ${ }^{9}$ Family and community medicine having its core competencies does not preclude it from sharing primary healthcare as a field of competence, or vice-versa. Even though McWhinney and Freeman have argued family medicine to be an academic discipline separate from other medical disciplines, ${ }^{21415}$ they also recognised distinctions among disciplines are sometimes more administrative and historical than epistemological. ${ }^{2}$

In Brazil, neither primary healthcare nor family and community medicine is acknowledged as a knowledge area in the official 'tree of knowledge' adopted by CAPES (the Federal Agency for Support and Evaluation of Graduate Education), CNPq (the National Council for Scientific and Technological Development) and FINEP (the Funding Authority for Studies and Projects). This means research grant applications and postgraduate programmes (master's and $\mathrm{PhD}$ degrees) must be registered in correlated knowledge areas, such as interdisciplinary, medicine or collective health, or in some subarea or specialty within those knowledge areas. In Latin America, 'collective health' comprises (among other definitions ${ }^{16}$ ) public health, epidemiology and humanities and social sciences in health. ${ }^{17}$

Accordingly, there are only a few postgraduate programmes on primary healthcare or Family Health ${ }^{18-21}$ (but no one on family and community medicine, that we know of) in Brazil, and university departments dedicated to primary healthcare and/or family and community medicine are exceedingly rare. Brazilian journals on primary healthcare and/or family and community medicine have little prestige, and thus a substantial part of relevant research is expected to be published in other, more general journals (this is not specific to Brazil $^{22}$ ). All this makes it very hard to gather a comprehensive understanding of postgraduate education and research in primary healthcare and/or family and community medicine.

In this study, we hope to shed some light on the postgraduate education of primary healthcare professionals in Brazil by using specialisation in family and community medicine as an indicator of likelihood of involvement with primary healthcare. Our objective was to explore their trajectories in postgraduate education (master's and $\mathrm{PhD}$ degree), describing the characteristics of their postgraduate degrees as well as correlating such degrees with characteristics of the physicians and their previous training.

\section{METHODS}

In this article, we report results from an observational, exploratory study, integrating administrative data from multiple sources: the Trajetorias MFC project.

\section{Data sources}

We compiled the list of family and community physicians in Brazil from two sources, corresponding to the two modes of recognition as a specialist for physicians in Brazil. ${ }^{23}$ One mode is certification by the corresponding specialty association. Such specialty certificates are conferred to physicians with either experience or a medical residency who pass an exam occurring once or twice every year, since $2003 .{ }^{38}$ We obtained the list of certified family and community physicians, as of late November 2018, from Sociedade Brasileira de Medicina de Família e Comunidade (SBMFC, the Brazilian Society of Family and Community Medicine), corresponding to the first 24 editions of the specialist certification exam. For physicians having renewed their certification (which is not required), we kept only data on their first certification.

The other way of being recognised as a specialist is completing a medical residency. In late December 2018, we downloaded spreadsheets from SisCNRM (the information system for medical residency) on both family and community medicine and general community medicine (ie, from after and before the specialty was renamed) and merged the lists. Again, for the few physicians having completed a medical residency more than once, we kept only data on their first medical residency.

After obtaining the data from both sources, we merged the lists into a single list of family and community physicians, using both the name and the CPF (Cadastro de Pessoas Físicas) registry identification number. We verified this compiled list extensively for internal consistency, resorting when necessary to searching the web and looking up in the Lattes Platform. Lattes Platform is the Brazilian information system on science, technology and innovation. Created in 1999, its curricula vitae (CVs) tend to be quite complete because they are used for decisions on research funding and recruitment, promotion and tenure. ${ }^{24}$ Furthermore, CVs in the Lattes Platform tend to be honest because researchers are accountable for the information they provide. For example, their individual CVs are publicly available as web pages and eXtensible Markup Language (XML) files.

After compiling the list of family and community physicians, we obtained the Lattes Platform ID number by looking up the Lattes Platform using the physicians' CPF numbers or names, and used this ID number to download 
the corresponding CVs in XML format in late December 2018. Data on the postgraduate courses were extracted from the Lattes XML files, and data entered manually by the physicians (instead of selecting from predefined lists) were verified by looking up the postgraduate programmes in the Sucupira Platform (the Brazilian information system on postgraduate programmes) ${ }^{25}$ and searching the web for the monographs. We then obtained further data on the postgraduate programmes from the Sucupira Platform using postgraduate programme ID codes found in the Lattes CVs. Because international programmes are not in the official lists or in the Sucupira Platform, we entered the code for the knowledge area and the mode of the master's degree by hand based on the programme title. We considered physicians without a Lattes CV as not having earned a master's degree nor $\mathrm{PhD}$.

\section{Variables}

We inferred gender from the physician's first name, using data from the 2010 Brazilian Census ${ }^{26}$ cached in the genderBR package V.1.1.0. ${ }^{27}$ First names were considered female if they had $50 \%$ or more probability of belonging to a woman, and male if otherwise; names appearing less than 20 times in the Census were not assigned any gender. The date when the Lattes CVs were last updated was retrieved from CVs themselves.

When the physician had both completed a medical residency and received a specialty certificate, we considered whichever came first as the mode of specialisation. The year of specialisation or completion of master's or $\mathrm{PhD}$ degree was categorised in 5-year periods, with the first period (up to 1998, the last year before the inception of the Lattes Platform) having an open beginning. Likewise, the states where the specialisation or completion of master's or $\mathrm{PhD}$ took place were grouped into the five geographical regions (North, Northeast, Southeast, South and Central-West), with an extra category for international postgraduate programmes (Supplemental Table in Fontenelle $e t a t^{28}$ lists data for individual states). The knowledge areas were handled at the 'basic knowledge area' level (ie, not at the 'greater knowledge area' level or the 'subarea' or 'specialty' levels), and areas other than medicine or collective health were grouped in a catchall category (Supplemental Table in Fontenelle et $a t^{28}$ lists data for individual basic knowledge areas). Master's degrees were also categorised according to their mode, that is, according to whether they were academic or professional. While both modes involve immersion in research, the academic master's courses aim to produce researchers, and the professional ones aim to produce better professionals for outside academia. ${ }^{29} 30$ Professional $\mathrm{PhD}$ courses are very recent, and we did not expect any degree to have been earned yet.

\section{Analysis}

Categorical data were described with absolute and relative frequencies, and continuous data were described with medians and IQRs. Besides describing gender and characteristics of specialisation and master's and $\mathrm{PhD}$ degrees, we also described the frequency of master's degrees among family and community physicians according to their gender and characteristics of specialisation, as well as the frequency of $\mathrm{PhD}$ degrees according to the same characteristics as well as to the characteristics of the master's degree. Because the interpretation of the year of specialisation depends on whether the specialisation was through medical residency or certification, year and mode of specialisation were merged into a single variable to describe the frequency of master's and $\mathrm{PhD}$ degrees.

The association of the beforementioned explanatory variables with having earned a master's degree (one response variable) or $\mathrm{PhD}$ (another response variable) was expressed with the odds ratio (OR). While the prevalence ratio could be more intuitive, the OR better approximates the incidence density (rate) ratio. ${ }^{31}$ The ORs were estimated through logistic regression both with a single and with multiple explanatory variables at a time, and were expressed as point estimates and $95 \%$ uncertainty intervals (UI). All regression coefficients (including the intercept) had weakly informative prior distributions, ${ }^{32}$ and inference was based on the No-U-Turn sampler. ${ }^{33}$ Year and mode of specialisation were entered in such regression models separately along with an interaction term between them but, for ease of understanding, the results were presented as if there was a single 'year and mode of specialisation' variable. In the multivariable model for the PhD degree, we opted for a hierarchical framework. ${ }^{34}$ The 'distal level' of the hierarchical framework included gender and characteristics of the specialisation, and the 'proximal level' included characteristics of the master's degree. Variables in the distal level had their OR adjusted for other variables in the distal level, and variables in the proximal level had their OR adjusted for all other variables in the model, from both levels.

Time from specialisation to master's and $\mathrm{PhD}$ degrees, and between the two later ones, was described both in general and according to the mode of specialisation. We also examined the distribution of the knowledge areas of the master's degrees according to the mode of specialisation, and the distribution of knowledge areas of PhD degrees according to the mode of specialisation and the knowledge area of the master's degree. We did not examine the distribution of the knowledge area of the $\mathrm{PhD}$ degree according to the mode of the master's degree, because too few family and community physicians with a professional master's degree earned a $\mathrm{PhD}$. When describing the distribution of the knowledge area of the $\mathrm{PhD}$ according to the knowledge area of the master's degree, we opted for an alluvial diagram.

The data were analysed using R V.3.6.1. ${ }^{35}$ While data verification by hand involved spreadsheet applications from office suites, most data processing (including the tabulation of frequencies) was done within $\mathrm{R}$ itself, using packages centred around the concept of 'tidy data', as well as packages specific to Brazilian data. ${ }^{27}{ }^{37}$ For 


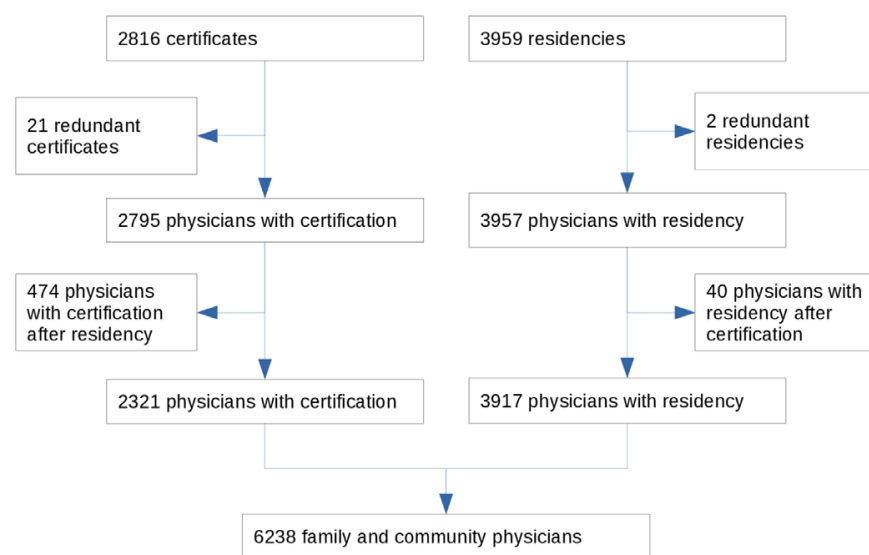

Figure 1 Flowchart of the compilation of the list of family and community physicians in Brazil, December 2018.

regression modelling we used brms V.2.10.0, ${ }^{38}$ which builds on the Stan probabilistic programming language ${ }^{39}$ through rstan V.2.19.2. ${ }^{40}$ The alluvial diagram was made with ggalluvial V.0.10.0. ${ }^{41}$

\section{Ethics}

While most of the data sources we used are publicly available, there were two privacy issues. First, the spreadsheet SBMFC provided us with the complete list of certificates (including the CPF number of most) is not publicly available as such. Second, while all data we obtained from the Lattes Platform are publicly available, they lied behind technology intended no hinder data mining. Thus, before initiating the data collection we obtained approval by the research ethics committee of Universidade Vila Velha (certificate 02957118.2.0000.5064). Because our data are personally identifiable, they will be available only if researchers present an ethically approved research project with an analysis plan. ${ }^{42}$

\section{RESULTS}

Figure 1summarises the compilation of the list of family and community physicians included in this study. The first 24 editions of the specialist certification exam resulted in the emission of 2816 certificates, amounting to 2795 unique physicians. Furthermore, 3959 medical residencies were completed (936 in general community medicine and 3023 after it was renamed family and community medicine), amounting to 3957 unique physicians. Because 514 physicians both concluded a medical residency and were certified, there were 6238 unique family and community physicians. Of these, 4065 (65.2\%) had a CV in the Lattes Platform. Median time since these CVs were last updated was 1 year, with an IQR of 0-4 years and a maximum of 18 years.

Most family and community physicians $(3563,57.1 \%)$ were female, and the most common mode of specialisation was medical residency $(3917,62.8 \%$, table 1$)$. The number of new family and community physicians increased over time, with the largest increases being from $1999-2003(5.9 \%)$ to $2004-2008(21.9 \%)$ and from
Table 1 Family and community physicians in Brazil, December 2018

\begin{tabular}{lrr}
\hline Characteristics & N & $\%$ \\
\hline Gender & & \\
\hline Female & 3563 & 57.1 \\
\hline Male & 2546 & 40.8 \\
\hline Not inferred & 129 & 2.1 \\
\hline Mode of specialisation* & & \\
\hline Certification & 2321 & 37.2 \\
\hline Medical residency & 3917 & 62.8 \\
\hline Year of specialisation & & \\
\hline 2014-2018 & 2364 & 37.9 \\
\hline 2009-2013 & 1573 & 25.2 \\
\hline 2004-2008 & 1368 & 21.9 \\
\hline 1999-2003 & 370 & 5.9 \\
\hline 1981-1998 & 563 & 9.0 \\
\hline Region of specialisation & & \\
\hline North & 314 & 5.0 \\
\hline Northeast & 825 & 13.2 \\
\hline Southeast & 2794 & 44.8 \\
\hline South & 1943 & 31.3 \\
\hline Central-West & 317 & 5.1 \\
\hline Unknown & 45 & 0.7 \\
\hline Nhichevis & & \\
\hline
\end{tabular}

*Whichever came first, for physicians specialising through both modes.

2009-2013 (25.2\%) to 2014-2018 (37.9\%). Specialisation in family and community medicine was concentrated in the Southeast and South regions.

A master's degree was obtained by 747 (12.0\%) family and community physicians (table 2), with $554(74.2 \%)$ degrees being academic and the other 193 (25.8\%) being professional. The number of new master's degrees increased with time, especially from 2004-2008 to 2009-2013; from 2009-2013 to 2014-2018, the increase was restricted to professional master's degrees. As for specialisation, master's degrees were concentrated in the Southeast and South regions, both for academic and professional degrees. Master's degrees in collective health $(351,47.0 \%)$ were twice as frequent as those in medicine $(170,22.8 \%)$, with other frequent knowledge areas being interdisciplinary $(84,11.2 \%)$, teaching $(30,4.0 \%)$ and education $(24,3.2 \%)$. Professional degrees accounted for $104(29.6 \%)$ of the master's degrees in collective health, but only $27(15.9 \%)$ of those in medicine. The postgraduate programmes were spread across 141 institutions, with only eight of them having conferred a master's degree to at least 20 family and community physicians. Most family and community physicians obtained their master's degrees from Universidade Federal do Rio Grande do Sul (UFRGS; Federal University of Rio Grande do Sul), Fundação Oswaldo Cruz (Fiocruz; Oswaldo Cruz Foundation) or Universidade de São Paulo (USP; University 
Table 2 Master's and PhD degrees of family and community physicians in Brazil, December 2018

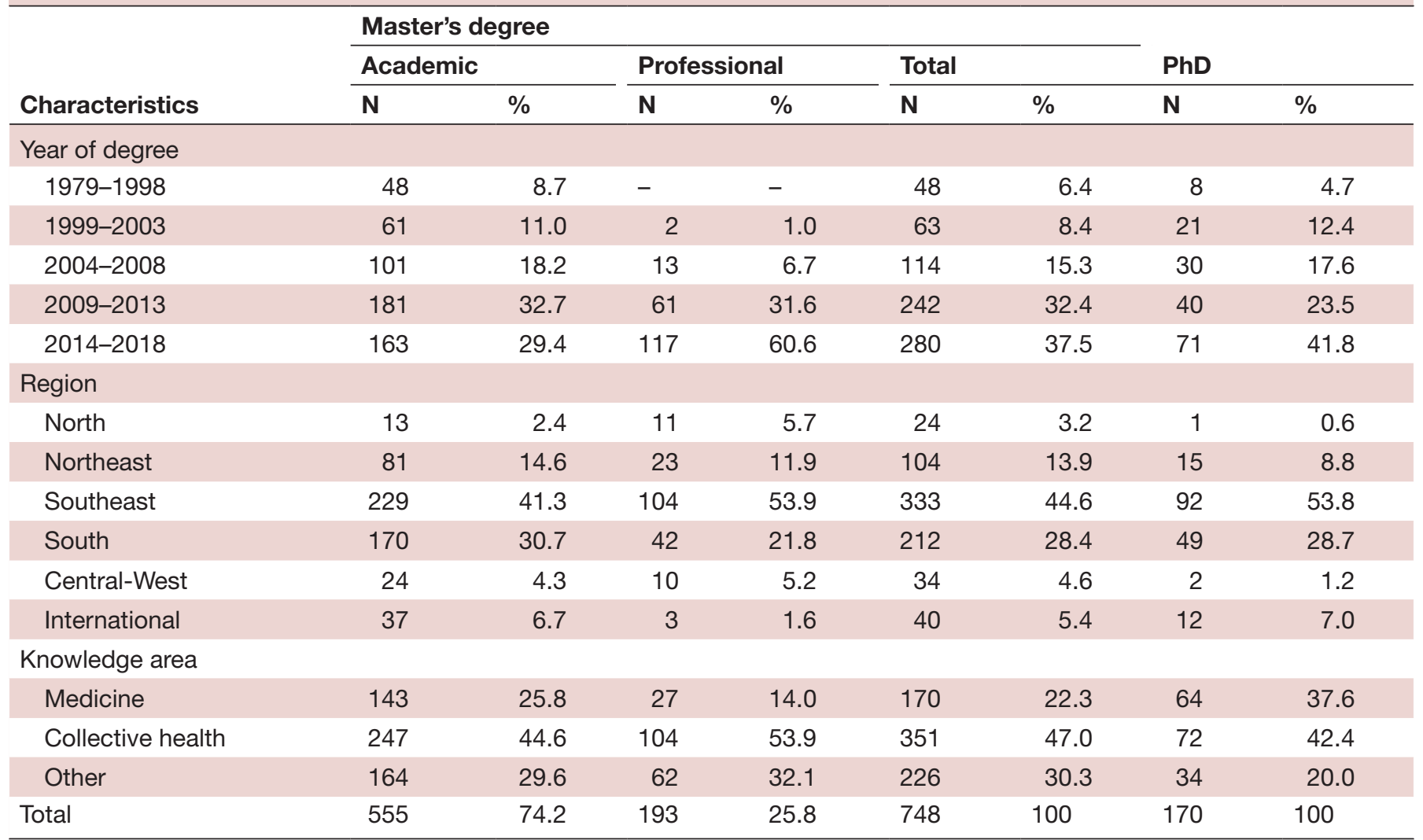

of São Paulo); more information on the Supplemental Table in Fontenelle et $a l .^{28}$

A PhD degree was held by $170(2.7 \%)$ family and community physicians (table 2). There were no professional $\mathrm{PhD}$ degrees. As with master's degrees, there was an increase in new $\mathrm{PhD}$ degrees over time, and most degrees were obtained in the Southeast and South regions of Brazil. Contrary to master's degrees, $\mathrm{PhD}$ degrees were more evenly distributed between medicine $(64,38 \%)$ and collective health $(72,42 \%)$. The postgraduate programmes were spread across 40 institutions, with only two of them (USP and UFRGS) having conferred more than 20 degrees; more information on the Supplemental Table in Fontenelle et $_{\text {al. }}{ }^{28}$

Some groups of family and community physicians were less likely to hold a master's or PhD degree, even after adjusting for other characteristics (tables 3 and 4). Women were less likely to hold a master's degree than their male colleagues, and only half as likely to hold a PhD. Family and community physicians with a professional master's degree were $1 / 7$ as likely to earn a $\mathrm{PhD}$ as those with an academic master's degree. A master's degree in other knowledge areas was also associated with a lower likelihood of earning a PhD than a master's in medicine or collective health.

Among those earning a master's degree, the median time from specialisation to master's degree was 4 years (IQR, 0-6): 5 years (IQR, 3-8) for family and community physicians specialising through medical residency, and
1 year (IQR, -3 to 4) for those specialising through certification. Earning a master's degree came before specialisation for $21.8 \%$ family and community physicians: $9.1 \%$ for those specialising through medical residency, and $39.9 \%$ for those specialising through certification. The proportion of master's degrees in each of the knowledge areas (medicine, collective health, other) was very similar across the specialisation modes (certification or medical residency, table 5).

Likewise, the median time from specialisation to $\mathrm{PhD}$ degree was 9 years (IQR, 3.25-12): 10 years (IQR, 7-14) for family and community physicians specialising through medical residency, and 2 years (IQR, -2.5 to 9 ) for those specialising through certification. Earning a PhD degree came before specialisation for $16 \%$ family and community physicians: $6 \%$ for those specialising through medical residency, and $33 \%$ for those specialising through certification. As with the master's degrees, the proportion of $\mathrm{PhD}$ degrees in each of the knowledge areas (medicine, collective health, other) was very similar across the specialisation modes (certification or medical residency, table 6).

Finally, the median time from master's to $\mathrm{PhD}$ degree was 4 years (IQR, $0-6)$. Most family and community physicians earning a $\mathrm{PhD}$ in collective health $(50,69 \%)$ also earned a master's degree in the same knowledge area (figure 2). On the other hand, half of those earning a $\mathrm{PhD}$ in medicine earned a master's degree in collective health $(11,17 \%)$ or no master's degree at all (ie, direct 
Table 3 Characteristics associated with holding a master's degree among family and community physicians in Brazil, 2018

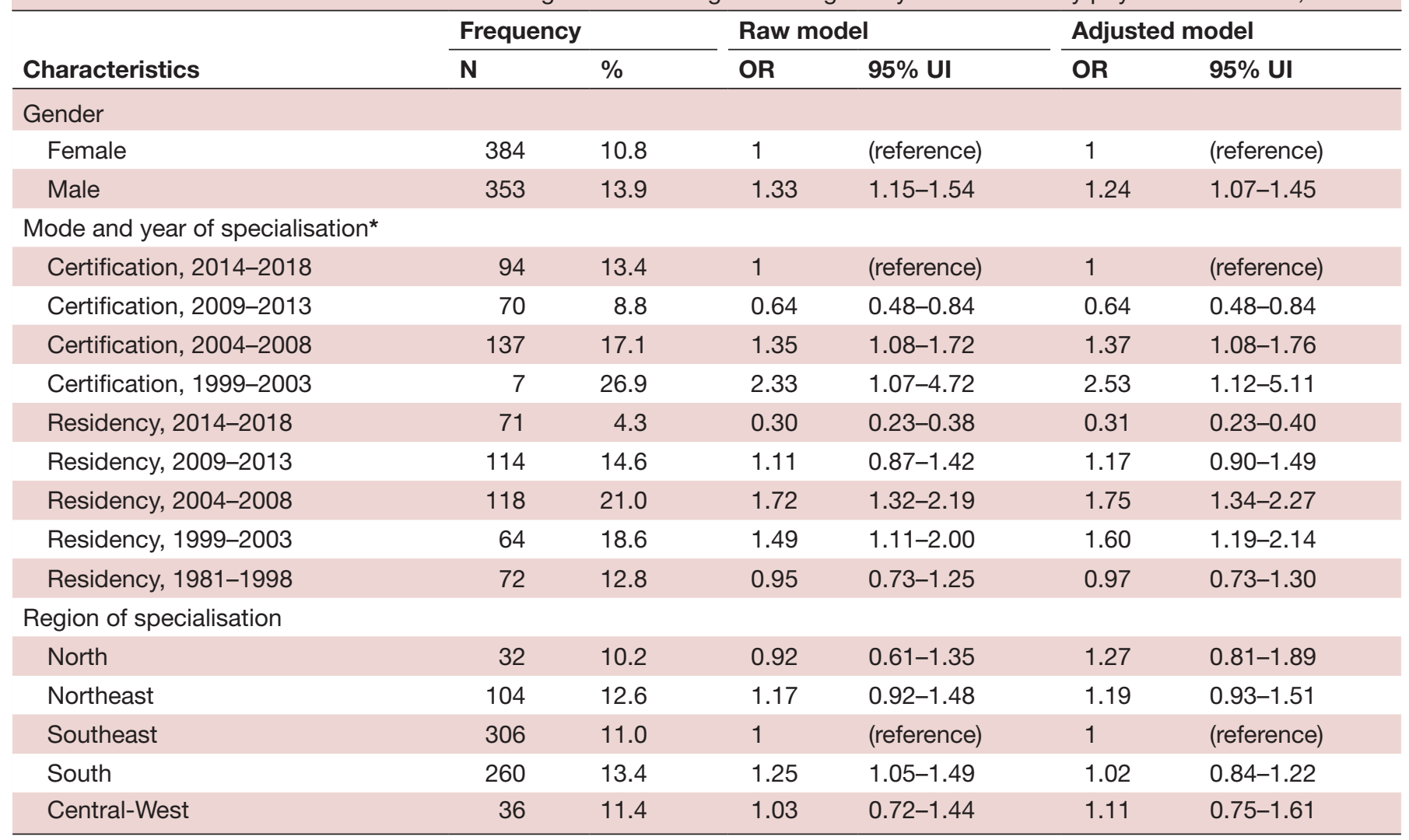

UI, uncertainty interval.

$\mathrm{PhD} ; 19,30 \%)$. Most direct $\mathrm{PhD}$ degrees $(16,53 \%)$, in medicine or otherwise, were conferred by USP.

\section{DISCUSSION}

Our findings indicate one in eight family and community physicians have earned a master's degree, and little more than 1 in 40 have earned a PhD. The number of new degrees is increasing over time, and most of the degrees are in collective health (not medicine) and were obtained in the Southeast and South regions. Gender is associated with the probability of obtaining a master's degree and, together with the mode and knowledge area of the master's degree, also with that of obtaining a PhD degree. In comparison to family and community physicians specialising through medical residency, those specialising through certification were more likely to already have earned a master's and/or PhD degree (instead of earning after specialisation), but just as likely to have earned their degree in medicine, collective health or other knowledge areas.

Professional master's programmes are responsible for most of the recent increase in the number of master's degrees, and might be attracting graduate students who would otherwise opt for academic programmes. The Northeast region, with its RENASF network of institutions offering a professional master's programme focused on the Family Health Strategy, ${ }^{19}{ }^{20}$ accounts for part of this increase, as does the state of Rio de Janeiro, whose capital city recently invested heavily in the expansion of the Family Health Strategy and incentivised health professionals to earn master's degrees ${ }^{21}$; but the increase in professional master's degrees was not restricted to these states (data not shown). Even though the ProfSaúde programme $^{18}$ is expected to contribute to this increase, it does not account for our findings, because its first students graduated after we obtained our data.

Brazil has been promoting professional master's degree on Family Health alongside other qualification initiatives, such as residencies, short postgraduate courses, and academic master's degree. ${ }^{21}{ }^{30}$ While one would expect any qualification to contribute something, responsible public policies for human resources in health depend on critically examining the relative benefits of the multiple possible postgraduate trajectories. For example, some qualification initiatives might add little to the performance of professionals who are already sufficiently qualified, or who are not qualified enough to benefit from said initiatives. Furthermore, for better or for worse, a professional master's degree should increase employability in academia (even if presumably not as much as an academic master's degree), thereby increasing workforce turnover in the Family Health Strategy while contributing to the education of the new generation of health professionals. 
Table 4 Characteristics associated with holding a PhD degree among family and community physicians in Brazil, 2018

\begin{tabular}{|c|c|c|c|c|c|c|}
\hline \multirow[b]{2}{*}{ Characteristics } & \multicolumn{2}{|c|}{ Frequency } & \multicolumn{2}{|c|}{ Raw model } & \multicolumn{2}{|c|}{ Adjusted model } \\
\hline & $\mathbf{N}$ & $\%$ & OR & $95 \%$ UI & OR & $95 \%$ UI \\
\hline \multicolumn{7}{|l|}{ Gender } \\
\hline Female & 70 & 2.0 & 1 & (reference) & 1 & (reference) \\
\hline Male & 96 & 3.8 & 1.96 & $1.45-2.69$ & 1.86 & $1.35-2.59$ \\
\hline \multicolumn{7}{|c|}{ Mode and year of specialisation* } \\
\hline Certification, 2014-2018 & 15 & 2.1 & 1 & (reference) & 1 & (reference) \\
\hline Certification, 2009-2013 & 7 & 0.9 & 0.46 & $0.22-0.93$ & 0.48 & $0.22-0.96$ \\
\hline Certification, 2004-2008 & 36 & 4.5 & 2.33 & $1.46-3.96$ & 2.40 & $1.45-4.11$ \\
\hline Certification, 1999-2003 & 5 & 19.2 & 10.99 & $4.10-26.10$ & 13.56 & $4.99-33.60$ \\
\hline Residency, 2014-2018 & 3 & 0.2 & 0.13 & $0.05-0.28$ & 0.14 & $0.06-0.31$ \\
\hline Residency, 2009-2013 & 13 & 1.7 & 0.79 & $0.41-1.52$ & 0.90 & $0.47-1.68$ \\
\hline Residency, 2004-2008 & 29 & 5.1 & 2.62 & $1.56-4.50$ & 2.75 & $1.63-4.83$ \\
\hline Residency, 1999-2003 & 23 & 6.7 & 3.47 & $2.01-6.27$ & 3.89 & $2.24-6.94$ \\
\hline Residency, 1981-1998 & 39 & 6.9 & 3.64 & $2.22-6.29$ & 3.85 & $2.31-6.78$ \\
\hline \multicolumn{7}{|l|}{ Region of specialisation } \\
\hline North & 2 & 0.6 & 0.23 & $0.05-0.73$ & 0.46 & $0.08-1.57$ \\
\hline Northeast & 16 & 1.9 & 0.72 & $0.41-1.22$ & 0.71 & $0.40-1.18$ \\
\hline Southeast & 74 & 2.6 & 1 & (reference) & 1 & (reference) \\
\hline South & 71 & 3.7 & 1.40 & $1.01-1.97$ & 0.76 & $0.53-1.09$ \\
\hline Central-West & 5 & 1.6 & 0.57 & $0.21-1.26$ & 0.72 & $0.24-1.66$ \\
\hline \multicolumn{7}{|l|}{ Mode of master's degree } \\
\hline Academic & 135 & 24.3 & 1 & (reference) & 1 & (reference) \\
\hline Professional & 5 & 2.6 & 0.08 & $0.03-0.19$ & 0.15 & $0.05-0.39$ \\
\hline \multicolumn{7}{|l|}{ Year of master's degree } \\
\hline 2014-2018 & 0 & 0.0 & 0.00 & $0.00-0.01$ & 0.00 & $0.00-0.02$ \\
\hline 2009-2013 & 48 & 19.8 & 0.20 & $0.10-0.37$ & 0.23 & $0.10-0.50$ \\
\hline 2004-2008 & 36 & 31.6 & 0.37 & $0.18-0.74$ & 0.38 & $0.17-0.86$ \\
\hline 1999-2003 & 28 & 44.4 & 0.65 & $0.30-1.35$ & 0.68 & $0.30-1.57$ \\
\hline $1979-1998$ & 28 & 58.3 & 1 & (reference) & 1 & (reference) \\
\hline \multicolumn{7}{|l|}{ Region of master's degree } \\
\hline North & 0 & 0.0 & 0.05 & $0.00-0.46$ & 0.08 & $0.00-1.12$ \\
\hline Northeast & 20 & 19.2 & 1.02 & $0.58-1.79$ & 1.09 & $0.42-2.65$ \\
\hline Southeast & 63 & 18.9 & 1 & (reference) & 1 & (reference) \\
\hline South & 44 & 20.8 & 1.13 & $0.74-1.76$ & 0.62 & $0.25-1.50$ \\
\hline Central-West & 3 & 8.8 & 0.41 & $0.10-1.23$ & 0.47 & $0.08-2.24$ \\
\hline International & 10 & 25.0 & 1.41 & $0.64-2.95$ & 0.57 & $0.20-1.47$ \\
\hline \multicolumn{7}{|c|}{ Knowledge area of master's degree $^{\dagger}$} \\
\hline Medicine & 42 & 24.7 & 1 & (reference) & 1 & (reference) \\
\hline Collective health & 68 & 19.4 & 0.75 & $0.48-1.18$ & 0.72 & $0.40-1.26$ \\
\hline Other & 30 & 13.3 & 0.47 & $0.28-0.80$ & 0.41 & $0.21-0.78$ \\
\hline None & 30 & 0.5 & 0.02 & $0.01-0.03$ & - & - \\
\hline
\end{tabular}

* Because specialist certification in family and community medicine began in 2003, few physicians were certified in 1999-2003, and none were certified before 1999.

†Category 'none' (no master's degree) was excluded from the multivariable regression model.

UI, uncertainty interval. 
Table 5 Knowledge area of master's degrees by mode of specialisation among family and community physicians in Brazil, December 2018

\begin{tabular}{|c|c|c|c|c|c|c|}
\hline \multirow[b]{2}{*}{ Mode of specialisation } & \multicolumn{2}{|c|}{ Medicine } & \multicolumn{2}{|c|}{ Collective health } & \multicolumn{2}{|c|}{ Other } \\
\hline & $\mathbf{N}$ & $\%$ & $\mathbf{N}$ & $\%$ & $\mathbf{N}$ & $\%$ \\
\hline Certification & 65 & 21.1 & 147 & 47.7 & 96 & 31.2 \\
\hline Residency & 105 & 23.9 & 204 & 46.5 & 130 & 29.6 \\
\hline
\end{tabular}

This debate is made even more timely by the advent of professional PhD programmes. Graduates from professional master's courses seem to be less likely to earn $\mathrm{PhD}$ degrees, even after adjusting for potential confounders, such as when was the master's degree concluded. Because graduates from professional programmes are expected to be outside academia, they might not find value in academic PhD courses. It remains to be seen if professional $\mathrm{PhD}$ programmes are needed to fill this niche, or if simply there's not much use for any PhD outside academia. Meanwhile, physicians are still not required to complete a medical residency (or otherwise be certified) before working in primary care in Brazil, and posts in medical residencies lag behind the annual number of newly graduated physicians (the same applies for nurses). ${ }^{43}$

Another major finding is that most family and community physicians hold master's and $\mathrm{PhD}$ degrees in collective health, not medicine. This phenomenon is more common for master's than for PhD degrees, and for professional than for academic degrees, but it occurs in both levels and both modes of postgraduate programmes. We cannot say this came as a surprise: of the authors who are family and community physicians, all three hold a $\mathrm{PhD}$ in a subarea of collective health. In our experience, not only has collective health devoted substantial interest to primary healthcare as a public policy, but also the Brazilian medical community has not devoted much interest to primary care as a locus of healthcare delivery. For example, searching for ('family medicine' OR 'family and community medicine') in the SciELO Brazil collection, one of the top five journals is on medical education and the other four are journals on collective health. This suggests most research on primary healthcare in Brazil to be on health policy, service management and health promotion, as well as medical education, but not so much on clinical care.

Most medical residencies, specialist certifications, master's and PhD degrees happened in the Southeast

Table 6 Knowledge area of PhD degrees by mode of specialisation among family and community physicians in Brazil, December 2018

\begin{tabular}{|c|c|c|c|c|c|c|}
\hline \multirow{2}{*}{$\begin{array}{l}\text { Mode of } \\
\text { specialisation }\end{array}$} & \multicolumn{2}{|c|}{ Medicine } & \multicolumn{2}{|c|}{$\begin{array}{l}\text { Collective } \\
\text { health }\end{array}$} & \multicolumn{2}{|c|}{ Other } \\
\hline & $\mathbf{N}$ & $\%$ & $\mathbf{N}$ & $\%$ & $\mathbf{N}$ & $\%$ \\
\hline Certification & 27 & 43 & 25 & 40 & 11 & 17 \\
\hline Residency & 37 & 35 & 47 & 44 & 23 & 21 \\
\hline
\end{tabular}

and South regions. The reason is twofold: these are two of the most populous regions (together with the Northeast region), and are the most economically developed ones. These facts also reflect in the overall distribution of physicians in Brazil. ${ }^{44}$ Interestingly, our data do not support a higher probability of obtaining a master's or $\mathrm{PhD}$ degree for family and community physicians specialising or obtaining a master's degree in the Southeast and South regions. This is not to say our data support equity in access to postgraduate programmes: there simply are too few family and community physicians outside the Southeast and South regions for us to make precise estimates. As the saying goes, 'absence of evidence is not evidence of absence (of effect), ${ }^{45}$

On the other hand, the association of gender and postgraduate degrees was very clear: female family and community physicians are less likely to obtain master's degrees than their male colleagues, and even less so for $\mathrm{PhD}$ degrees. This should not be interpreted as gender having a direct effect on educational achievement: our study was exploratory, and inclusion of gender as an explanatory variable was motivated mostly by the SAGER (Sex and Gender Equity in Research) guidelines. ${ }^{46}$ Rather, this finding should be taken as justification

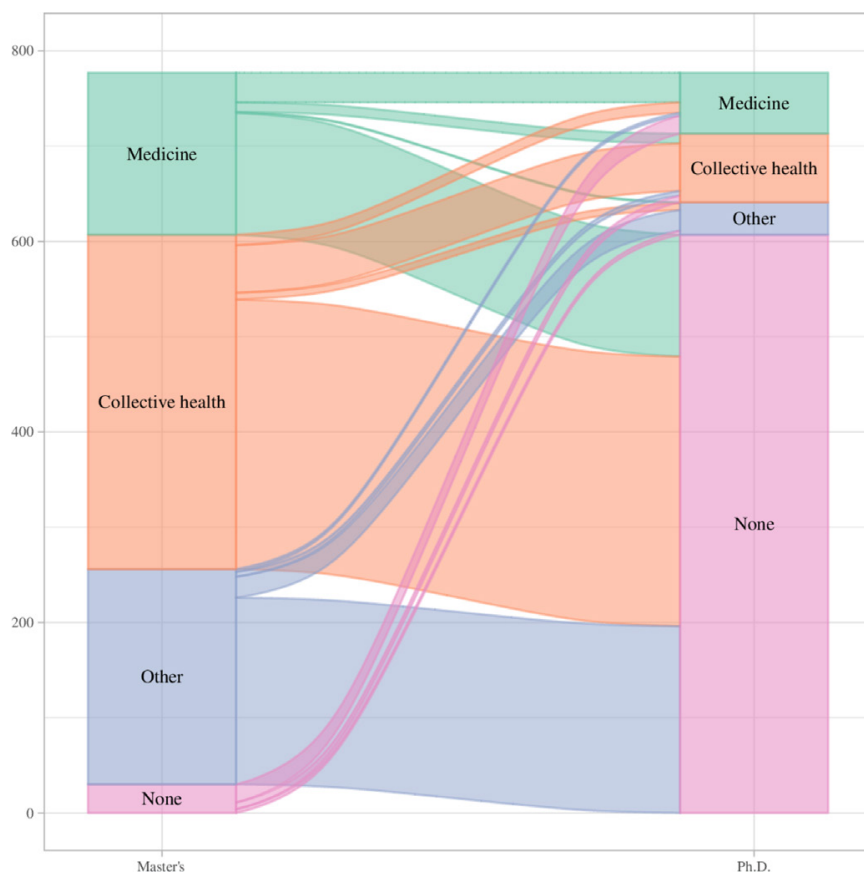

Figure 2 Alluvial diagram of knowledge areas for master's and $\mathrm{PhD}$ degrees of family and community physicians in Brazil, 2018. 
for further studies, aimed at a more proper explanation for this correlation. Such an explanation might have more to do with family and community medicine than with the Brazilian society at large, because half the master's and $\mathrm{PhD}$ graduates in Brazil are women. ${ }^{47}$ Besides the ethical relevance of elucidating and preferably removing any gendered barriers to postgraduate education, the issue has special relevance to the discipline because most family and community physicians are women.

In interpreting our findings, one must keep in mind we depended on administrative data. Because data from Conselho Federal de Medicina (CFM; the Federal Board of Medicine) is not available to others, we could not perform record linkage to identify who had retired, emigrated or deceased. The National Registration of Specialists was expected to provide easy access to an authoritative list of physicians in any medical specialty but, unfortunately, it has not been maintained as prescribed by the More Doctors Law. ${ }^{48}$ Consequently, the number of family and community physicians is surely overestimated, even if we expect this overestimation to be minor because family and community medicine is a fairly young specialty in Brazil. ${ }^{44}$ In 2018, Augusto et $a l^{23}$ (using the same methods as us) estimated there would be 5,438 family and community physicians in Brazil, 276 (5\%) more than the 5,162 found by Scheffer $e t a l,{ }^{44}$ who had access to CFM data. Another limitation of our study was that, as in Augusto $e t a l,{ }^{23}$ we could not include the family and community physicians who completed their medical residencies in the 1970s. SisCNRM records for family and community medicine (then community general medicine) begin at 1981, when the specialty was recognised; we can only hope family and community physicians from the 1970 s eventually took the exams and were certified after 2003.

Our data had limitations concerning postgraduate programmes, as well. Postgraduate degrees will probably have been underreported to some extent, even though postgraduate students are incentivised to have a CV in the Lattes Platform and entering data on a postgraduate degree is simple enough. Furthermore, there surely was some information error in the reported degrees, but we hope to have cleaned most of those errors during our verification. One potential issue is that we verified the data using current information on the postgraduate programmes, not information from when the degrees were obtained; but much of the information is not expected to change in any significant way, and possible changes in the knowledge subarea or specialty of the postgraduate programmes would not matter for our analysis, which was done at the level of basic knowledge area. Finally, because the Lattes Platform was launched in 1999, master's and $\mathrm{PhD}$ degrees earned before are expected to be underreported, even if this underreporting is expected to occur mostly among those who do not make much use of the degrees.

\section{CONCLUSION}

Family and community physicians in Brazil increasingly earn academic and professional master's and $\mathrm{PhD}$ degrees, with an emphasis on collective health, even though women seemingly face barriers to advance their education. The consequences of different postgraduate trajectories on professional performance and primary care research are unknown. We suggest it would be easier to gain a wider view of postgraduate education of primary care providers and/or on primary healthcare if the National Registration of Specialists came back online, and if primary healthcare and/or family and community medicine were recognised as knowledge areas.

Twitter Leonardo Ferreira Fontenelle @doutorleonardo and Thiago Dias Sarti @ dias_sarti

Acknowledgements MHMd0 received a scientific initiation scholarship from UVV. Contributors LFF, DJB and TDS helped in study conceptualisation. LFF, SVR and MHMdO performed data curation. Formal analysis was done by LFF. Investigation was done by LFF, SVR and MHMdO. LFF, DJB and TDS discussed the methodology. LFF helped in project administration, software management and visualisation. LFF and SVR helped in writing the original draft. Writing (review and editing) was done by SVR, MHMdO, DJB and TDS.

Funding The authors have not declared a specific grant for this research from any funding agency in the public, commercial or not-for-profit sectors.

Competing interests LFF and DJB are board members of Associação Capixaba de Medicina de Família e Comunidade (ACMFC), an organisation affiliated to Sociedade Brasileira de Medicina de Família e Comunidade (SBMFC).

Patient consent for publication Not required.

Ethics approval Research Ethics Committee of Universidade Vila Velha, report ${ }^{\circ}$ 3033911, certificate [CAAE] 02957118.2.0000.5064.

Provenance and peer review Not commissioned; externally peer reviewed.

Data availability statement Data are available upon reasonable request. Because our data are personally identifiable, it will be available to other researchers presenting an ethically approved research project with an analysis plan. https://doi. org/10.5281/zenodo.3376310.

Open access This is an open access article distributed in accordance with the Creative Commons Attribution Non Commercial (CC BY-NC 4.0) license, which permits others to distribute, remix, adapt, build upon this work non-commercially, and license their derivative works on different terms, provided the original work is properly cited, appropriate credit is given, any changes made indicated, and the use is non-commercial. See: http://creativecommons.org/licenses/by-nc/4.0/.

\section{ORCID iDs}

Leonardo Ferreira Fontenelle http://orcid.org/0000-0003-4064-433X

Stephani Vogt Rossi http://orcid.org/0000-0002-6090-6926

Miguel Henrique Moraes de Oliveira http://orcid.org/0000-0001-9720-6926

Diego José Brandão http://orcid.org/0000-0002-5000-3256

Thiago Dias Sarti http://orcid.org/0000-0002-1545-6276

\section{REFERENCES}

1 Bonet O. Os médicos da pessoa: um olhar antropológico sobre a medicina de família no Brasil e na Argentina. Rio de Janeiro: 7Letras, 2014.

2 Freeman T, McWhinney IR. McWhinney's textbook of family medicine. 4th edition. Oxford ; New York: Oxford University Press, 2016.

3 Anderson MIP, Gusso GDF. Medicina de família e comunidade: especialistas em integralidade. Rev APS 2005;8:61-7.

4 Weggemans MM, van Dijk B, van Dooijeweert B, et al. The Postgraduate medical education pathway: an international comparison. GMS J Med Educ 2017;34:Doc63.

5 Arya N, Gibson C, Ponka D, et al. Family medicine around the world: overview by region. Can Fam Physician 2017;63:436-41.

6 Hutt P. General practice in the United Kingdom - a training evolution. Rev Bras Med Fam Comunidade 2014;9:77-82. 
7 Aguiar DS. A saúde da família no Sistema Único de Saúde: Um novo paradigma? [Dissertation (Masters)]. Rio de Janeiro (BR), Fundação Oswaldo Cruz, Escola Nacional de Saúde Pública Sergio Arouca, 1998. https://www.arca.fiocruz.br/handle/icict/4673 [Accessed 2 Nov 2018]

8 Falk JW. A medicina de família e comunidade e sua entidade nacional: histórico e perspectivas. Rev Bras Med Fam Comunidade 2004;1:5-10.

9 Sól NAA. A medicina geral comunitária no Brasil: uma análise institucional sócio-histórica de sua trajetória enfocando programas específicos [Dissertation (Masters)]. Campinas (BR), Universidade Estadual de Campinas, Faculdade de Ciências Médicas, 2011. http:// www.repositorio.unicamp.br/handle/REPOSIP/312118 [Accessed 12 Aug 2019].

10 Andrade HS, Alves MGM, Carvalho SR, et al. A formação discursiva da medicina de família e comunidade no Brasil. Physis 2018;28.

11 Ministério da Saúde (BR), Secretaria de Atenção Saúde. Memórias da saúde da familia no Brasil. Brasília - DF: Departamento de Atenção Básica, 2010.

12 Ministério da Saúde (BR), Fundação Nacional da Saúde. Programa Saúde da Família: saúde dentro de casa. Brasília: Ministério da Saúde, 1994

13 Campos GWS, Chakour M, Santos RC. Análise crítica sobre especialidades médicas e estratégias para integrá-las ao Sistema Único de Saúde (SUS). Cad Saude Publica 1997;13:141-4.

14 Freeman T. Family Medicine's academic contributions. Family Medicine Research Days, İzmir, Turkey. Turk aile hekim derg 2012;16:181-98.

15 McWhinney IR. General practice as an academic discipline. reflections after a visit to the United States. Lancet 1966:1:419-23.

16 Osmo A, Schraiber LB. The field of collective health: definitions and debates on its constitution. Saude Soc 2015;24:205-18.

17 Vieira-da-Silva LM, Pinell P. The genesis of collective health in Brazil. Sociol Health IIIn 2014;36:432-46.

18 Teixeira CP, Guilam MCR. Concepção pedagógica e construção do currículo na pósgraduação strito sensu de um programa em rede nacional (ProfSaúde). In: Oliveira JF, ed. Gestão pedagógica, organização curricular, qualidade da educação, direitos humanos, diversidade cultural e inclusão social. Brasília: ANPAE, 2018. Available: http://www.anpae.org.br/BibliotecaVirtual/12-Congressos/ Volume3.pdf\#page $=43$

19 Monteiro CFS, Vieira APGF. Professional qualification in family health in the Northeast: the RENASF model. Rev Enferm UFPI 2016;5:1-6.

20 Dias MSA, Vieira-Meyer A. Rede de formação em saúde da família: a experiência do Nordeste brasileiro. Estudios Avanzados 2015;24:76-89.

21 Engstrom EM, Motta JI, Venâncio SA, et al. Training of professionals in post-graduation courses in public health and primary healthcare in the municipality of Rio de Janeiro, Brazil. Cien Saude Colet 2016;21:1461-70.

22 Peleg R, Shvartzman P. Where should family medicine papers be published - following the impact factor? J Am Board Fam Med 2006;19:633-6.

23 Augusto DK, David L, Ornelas Pereira Salvador de Oliveira D, et al Quantos médicos de família E comunidade temos no Brasil? Rev Bras Med Fam Comunidade 2018;13:1-4.

24 Lane J. Let's make science metrics more scientific. Nature 2010;464:488-9.

25 Siqueira MB. Sucupira - A Platform for the Evaluation of Graduate Education in Brazil. Procedia Comput Sci 2019;146:247-55.
26 No author. Nomes mais frequentes. Rio de Janeiro: Instituto Brasileiro de Geografia e Estatística, 2016. https://censo2010.ibge. gov.br/nomes/nota.tecnica.pdf

27 Meireles F, 2018genderBR: predict gender from Brazilian first names. Available: https://CRAN.R-project.org/package $=$ genderBR

28 Fontenelle LF, Rossi SV, OliveiraMHM, et al. Postgraduate education among family and community physicians in Brazil: the Trajetórias MFC project.

29 Ribeiro RJ. O mestrado profissional na política atual da Capes. RBPG 2005;2:8-15.

30 Saupe R, Wendhausen ÁLP. The professional master's degree as a preferable model for training in family health. Interface 2005;9:621-30.

31 Reichenheim ME, Coutinho ESF. Measures and models for causal inference in cross-sectional studies: arguments for the appropriateness of the prevalence odds ratio and related logistic regression. BMC Med Res Methodol 2010;10:66.

32 Gelman A, Jakulin A, Pittau MG, et al. A weakly informative default prior distribution for logistic and other regression models. Ann Appl Stat 2008;2:1360-83.

33 Hoffman MD, Gelman A. The No-U-Turn sampler: adaptively setting path lengths in Hamiltonian Monte Carlo. J Mach Learn Res 2014;15:1593-623.

34 Victora CG, Huttly SR, Fuchs SC, et al. The role of conceptual frameworks in epidemiological analysis: a hierarchical approach. Int $J$ Epidemiol 1997;26:224-7.

35 R Core Team. R: A Language and Environment for Statistical Computing, 2019. Vienna, Austria: R foundation for statistical computing. Available: https://www.R-project.org/ [Accessed 19 Aug 2019]

36 Wickham H. Tidy data. J Stat Softw 2014;59:1-23.

37 Freitas W. numbersBR: Validate, Compare and Format Identification Numbers from Brazil, 2018. Available: https://CRAN.R-project.org/ package=numbersBR [Accessed 19 Aug 2019].

38 Bürkner P-C. brms: an R package for Bayesian multilevel models using Stan. J Stat Softw 2017;80:1-28.

39 Carpenter B, Gelman A, Hoffman MD, et al. Stan : A Probabilistic Programming Language. J Stat Softw 2017;76:1-32.

40 Guo J, Gabry J, Goodrich B. rstan: R interface to Stan, 2019. Available: https://CRAN.R-project.org/package=rstan

41 Brunson JC. ggalluvial: Alluvial Diagrams in 'ggplot2', 2019. Available: https://CRAN.R-project.org/package=ggalluvial

42 Fontenelle LF, Rossi SV, OliveiraMHM. Postgraduate education among family and community physicians in Brazil: the Trajetórias MFC project. Zenodo 2019; Published Online First: 20 September 2019.

43 Mash R, Almeida M, Wong WCW, et al. The roles and training of primary care doctors: China, India, Brazil and South Africa. Hum Resour Health 2015;13:93

44 Scheffer M. Demografia médica no Brasil 2018. São Paulo: Departamento de Medicina Preventiva da Faculdade de Medicina da USP; Conselho Regional de Medicina do Estado de São Paulo; Conselho Federal de Medicina, 2018.

45 Altman DG, Bland JM. Statistics notes: absence of evidence is not evidence of absence. BMJ 1995;311:485

46 Heidari S, Babor TF, Castro PD, et al. [Sex and Gender Equity in Research: rationale for the SAGER guidelines and recommended use]. Epidemiol Serv Saude 2017;26:665-76.

47 OECD. Education at a glance 2019: OECD indicators. OECD 2019.

48 Pinto HA, Andreazza R, Ribeiro RJ, et al. The more doctors program and the changing role of the state in the regulation and organization of medical education. Interface 2019;23:e170960. 